\title{
Antioxidant, Anti-Nephrolithe Activities and in Vitro Digestibility Studies of Three Different Cyanobacterial Pigment Extracts
}

\author{
Chetan Paliwal ${ }^{1,2, \dagger}$, Tonmoy Ghosh ${ }^{1,2, \dagger}$, Khushbu Bhayani ${ }^{1}$, Rahulkumar Maurya ${ }^{1,2}$ and \\ Sandhya Mishra $1,2, *$
}

1 Salt and Marine Chemicals, CSIR-Central Salt and Marine Chemicals Research Institute, Bhavnagar 364002, India; E-Mails: paliwalchetan@gmail.com (C.P.); forghosh@gmail.com (T.G.); khushboobhayani@gmail.com (K.B.); maurya.micro@gmail.com (R.M.)

2 Academy of Scientific \& Innovative Research (AcSIR), CSIR-Central Salt and Marine Chemicals Research Institute, Bhavnagar 364002, India

$\dagger$ These authors contributed equally to this work.

* Author to whom correspondence should be addressed; E-Mail: smishra@csmcri.org; Tel.: +91-278-256-5801 or +91-278-256-3805 (ext. 6160); Fax: +91-278-256-6970 or $+91-278-256-7562$.

Academic Editor: Colin Barrow

Received: 2 June 2015 / Accepted: 10 August 2015 / Published: 20 August 2015

\begin{abstract}
Phycobiliprotein-containing water and carotenoid-containing methanolic extracts of three different cyanobacteria, Pseudanabaena sp., Spirulina sp. and Lyngbya sp., were studied for their DPPH scavenging, iso-bolographic studies, and anti-nephrolithe activities. The best $\mathrm{EC}_{50}$ values for DPPH scavenging were in Lyngbya water (LW, $\left.18.78 \pm 1.57 \mathrm{mg} \cdot \mathrm{mg}^{-1} \mathrm{DPPH}\right)$ and Lyngbya methanol $\left(\mathrm{LM}, 59.56 \pm 37.38 \mathrm{mg} \cdot \mathrm{mg}^{-1} \mathrm{DPPH}\right)$ extracts. Iso-bolographic analysis revealed most of the combinations of extracts were antagonistic to each other, although LM-Spirulina methanol (SM) 1:1 had the highest synergistic rate of $86.65 \%$. In vitro digestion studies showed that DPPH scavenging activity was considerably decreased in all extracts except for Pseudanabaena methanol (PM) and LM after the simulated digestion. All of the extracts were effective in reducing the calcium oxalate crystal size by nearly $60 \%-65 \%$ compared to negative control, while PM and Spirulina water (SW) extracts could inhibit both nucleation and aggregation of calcium oxalate by nearly $60 \%-80 \%$.
\end{abstract}


Keywords: Carotenoids; phycobiliproteins; Antioxidants; iso-bolographic analysis; calcium oxalate crystallization; in vitro digestibility; DPPH

\section{Introduction}

Microalgae are ecumenical, photosynthetic, prokaryotic organisms found in diverse habitats and extreme environmental conditions covering both aquatic and terrestrial territories [1]. They are a source of primary productivity in an aquatic ecosystem. Estimates have calculated the productivity of microalgae within a range of one-third to more than half of the global primary productivity $[2,3]$. They have the capacity to adjust in varying adverse environmental conditions. Being such prolific organisms, they are a storehouse of various commercially important and beneficial compounds like phycobiliproteins, carotenoids, polysaccharides, vitamins, polyhydroxyalkanoates, and biocides [4-8]. Phycobiliproteins and carotenoids, respectively, are water- and lipid-soluble pigments, polysaccharides are complex carbohydrates which can be used as emulsifiers, polyhydroxyalkanoates are a group of compounds which can be used as biodegradable plastics, while biocides are anti-bacterial, anti-fungal, anti-viral or even anti-algal compounds. There is a huge market demand for these important bioactive compounds, which has provided a thrust in their research and development [9]. Among these, water-soluble phycobiliproteins and lipo-soluble carotenoids play a key role in light harvesting and protection from photo-oxidative stress. These compounds have also been center of attraction due to their natural antioxidant potential with outstanding properties to fight against oxidative stress, cancer, aging, and other degenerative diseases [10-12].

Urolithiasis has been a frequently seen problem in humans and it affects a large section of the human population. In more than $80 \%$ of the cases these are calcium rich stones formulated by either oxalate or phosphate. Crystallization of these stones is affected by various physicochemical events, such as nucleation, growth, and aggregation. Recent studies suggest that antioxidants and free radical scavengers have an ability to counter the occurrence and reoccurrence of urinary stones [13].

The integration of these biologically-active pigments in food products would increase their nutritional and health benefits. Recently, great interest has developed in the in vitro model for food delivery systems to study the release of desired compounds that will benefit human health [14]. In vitro digestion processes are widely used to gain an insight into the gastrointestinal changes that a food will undergo; for example, structural changes and release of specific components, under controlled gastrointestinal conditions. In vitro digestion methods have advantages over in vivo methods because of their rapidity, economics, labor requirements, and lack of any ethical issues. There have been several in vitro digestibility studies carried out on variety of natural compounds to assess their bioavailability but studies have been lacking on pigment extracts of cyanobacteria, although there have been in vitro digestibility studies on synthetic carotenoids absorption in humans [15]. This method provides an acceptable validation of the digestive process in comparison with in vivo tests [16].

The aim of this study is to investigate the free radical scavenging activities of water and methanolic extracts of three chosen cyanobacterial strains and also to observe the synergistic effects when these extracts are mixed with each other in different proportions. It also aims to conduct studies on the 
in vitro digestibility of the said extracts and to evaluate their potential for free radical scavenging after the digestion process. This study would enhance our current knowledge about the behavior of cyanobacterial pigments and their antioxidant activities before and after digestion. Further, it also aims to investigate the effects of these extracts on the inhibition of calcium oxalate crystallization, the most common cause of urolithiasis.

\section{Results and Discussion}

\subsection{Characterization of Extracts}

The extracts were characterized as shown in Section 3.2. The phycobiliprotein profile of water and carotenoid profile of methanolic extracts have been presented in Table 1. The Spirulina water (SW) extract had C-phycocyanin (C-PC) as the major pigment $\left(11.62 \pm 0.30 \mathrm{mg} \cdot \mathrm{g}^{-1}\right)$. Similarly, the Spirulina methanolic (SM) extract had echinenone as the major carotenoid $\left(0.38 \pm 0.04 \mathrm{mg} \cdot \mathrm{g}^{-1}\right)$ with a $\beta$-carotene content of $0.23 \pm 0.02 \mathrm{mg} \cdot \mathrm{g}^{-1}$. The Pseudanabaena water $(\mathrm{PW})$ extract had C-phycoerythrin (C-PE) as the major pigment $\left(9.45 \pm 0.45 \mathrm{mg} \cdot \mathrm{g}^{-1}\right)$, while its methanolic (PM) extract mainly contained zeaxanthin $\left(0.29 \pm 0.02 \mathrm{mg} \cdot \mathrm{g}^{-1}\right)$. Lyngbya water (LW) extract had C-PE as the major pigment $\left(108.76 \pm 2.18 \mathrm{mg} \cdot \mathrm{g}^{-1}\right)$, while its methanolic $(\mathrm{LM})$ extract mainly contained $\beta$-carotene $\left(0.17 \pm 0.03 \mathrm{mg} \cdot \mathrm{g}^{-1}\right)$. All the values have been reported in triplicate on a dry mass basis.

Table 1. Phycobiliprotein and carotenoid profile of water and methanolic extracts, respectively, for different cyanobacterial species $\left(\mathrm{mg} \cdot \mathrm{g}^{-1}\right.$ dry mass, $\left.n=3\right)$.

\begin{tabular}{|c|c|c|c|c|}
\hline \multicolumn{2}{|c|}{ Compounds (mg $\cdot \mathrm{g}^{-1}$ dry mass) } & \multirow{2}{*}{$\begin{array}{c}\text { Pseudanabaena sp. } \\
6.96 \pm 0.34\end{array}$} & \multirow{2}{*}{$\frac{\text { Spirulina sp. }}{11.62 \pm 0.3}$} & \multirow{2}{*}{$\begin{array}{c}\text { Lyngbya sp. } \\
107.92 \pm 1.79\end{array}$} \\
\hline \multirow{3}{*}{ Phycobiliproteins (Water extract) } & $\mathrm{C}-\mathrm{PC}{ }^{\text {a }}$ & & & \\
\hline & $\mathrm{A}-\mathrm{PC}$ a & $2.94 \pm 0.2$ & $3.87 \pm 0.11$ & $21.64 \pm 0.75$ \\
\hline & C-PE ${ }^{a}$ & $9.45 \pm 0.45$ & $0.93 \pm 0.02$ & $108.76 \pm 2.18$ \\
\hline \multirow{7}{*}{ Carotenoids (Methanol extract) } & Myxoxanthophyll & $0.05 \pm 0.01$ & $0.02 \pm 0.00$ & $0.05 \pm 0.02$ \\
\hline & Zeaxanthin & $0.29 \pm 0.02$ & $0.12 \pm 0.01$ & $0.15 \pm 0.13$ \\
\hline & Canthaxanthin & $0.11 \pm 0.01$ & $0.04 \pm 0.00$ & $0.04 \pm 0.01$ \\
\hline & Lycopene & $0.12 \pm 0.01$ & $0.17 \pm 0.02$ & $\mathrm{ND}^{\mathrm{a}}$ \\
\hline & $\alpha$-carotene & $0.08 \pm 0.00$ & $0.09 \pm 0.01$ & $0.10 \pm 0.02$ \\
\hline & $\beta$-carotene & $0.27 \pm 0.02$ & $0.23 \pm 0.02$ & $0.17 \pm 0.03$ \\
\hline & Echinenone & $\mathrm{ND}^{\mathrm{a}}$ & $0.38 \pm 0.04$ & $\mathrm{ND}^{\mathrm{a}}$ \\
\hline Chlorophyll (Methanol extract) & Chlorophyll a & $0.70 \pm 0.03$ & $4.80 \pm 0.51$ & $1.5 \pm 0.03$ \\
\hline
\end{tabular}

${ }^{a}$ C-PC: C-phycocyanin, A-PC: allophycocyanin, C-PE: C-phycoerythrin, ND: not detected.

Morist et al. have reported C-PC content of $40 \mathrm{mg} \cdot \mathrm{g}^{-1}(\mathrm{w} / \mathrm{w})$ in Spirulina platensis cultured in a photobioreactor, while Mishra et al. have reported a C-PE content of $25.6 \mathrm{mg} \cdot \mathrm{g}^{-1}$ in Pseudanabaena sp. after $60 \%$ ammonium sulphate fractionation [17,18]. In another reported study, Anabaena sp. was reported to contain approximately $83 \mathrm{mg} \cdot \mathrm{g}^{-1}$ of C-PE [19]. 
If we compare the lipophilic carotenoids in these three species with earlier reported values, Aakermann et al. have reported $1.3 \mathrm{mg} \cdot \mathrm{g}^{-1}$ total carotenoids in Spirulina platensis out of which $0.46 \mathrm{mg}$ was $\beta$-carotene and $0.03 \mathrm{mg}$ was echinenone. They have also reported similar figures for echinenone and $\beta$-carotene in another Spirulina subsalsa strain [20]. Singh has reported total carotenoid content ranging from $0.18 \pm 0.00$ to $9.74 \pm 0.53 \mathrm{mg} \cdot \mathrm{g}^{-1}$ of several different Lyngbya $\mathrm{sp}$. strains [21]. They have also reported the total carotenoid content in three Pseudanabaena species in a range of $4.44 \pm 0.67$ to $6.64 \pm 0.28 \mathrm{mg} \cdot \mathrm{g}^{-1}$.

\subsection{Antioxidant Activities}

\subsubsection{Total Phenolic Content (TPC)}

The total phenolic content of the methanol and water extracts have been shown in Figure 1a,b, respectively. The extracts were diluted to five different concentrations which were then evaluated according to the method detailed in Section 3.3.1. The phenolic content decreased with the dilution of the extracts. In case of water extracts, the highest phenolic content was seen in LW extract $(278.73 \pm 1.24$ mg gallic acid equivalent (GAE) $\mathrm{g}^{-1}$ dry mass), followed by SW extract $\left(119.19 \pm 2.09 \mathrm{mg} \mathrm{GAE} \mathrm{g}^{-1}\right.$ dry mass). The same trend was observed when the methanolic extracts were considered. The highest phenolic content was observed in LM extract (12.77 $\pm 2.23 \mathrm{mg} \mathrm{GAE} \mathrm{g}^{-1}$ dry mass), with SM extract placing second $\left(0.66 \pm 0.3 \mathrm{mg}\right.$ GAE $\mathrm{g}^{-1}$ dry mass $)$. The PW and PM extracts contained the lowest amount of phenolic content. All the values have been presented in triplicate. Jiang et al. have reported phenolic contents of four different vegetable extracts in a range of $0.64 \pm 0.04$ to $8.88 \pm 0.59 \mathrm{mg}$ $\mathrm{GAE} \mathrm{g}^{-1}$ dry mass [22]. Machu et al. have reported phenolic contents of $43.2 \pm 1.0 \mathrm{mg} \mathrm{GAE} \mathrm{g}^{-1}$ from edible dried Spirulina platensis when extracted in heated distilled water [23]. When using 100\% methanol, the corresponding value is $24.4 \pm 0.2 \mathrm{mg} \mathrm{GAE} \mathrm{g}^{-1}$. However, we have utilized the same biomass for both water and methanol extraction, which accounts for the lower phenolic content in the methanol extracts. Ismaiel et al. have reported phenolic contents of 1-10 $\mathrm{mg} \mathrm{GAE} \mathrm{g}^{-1}$ dry mass from the water extracts of eleven different cyanobacterial strains with the highest content in Spirulina platensis [24]. In the present study, both LW and SW can contribute to various biological activities due to the considerably higher phenolic content. These phenolics are thought to play an important role in the antioxidant activity of the respective extracts by donating electrons. However, the total phenolic content of an extract is often more meaningful, both scientifically and economically, instead of extracting and purifying different phenolic compounds individually, since they may act co-operatively with each other rather than alone [25]. 


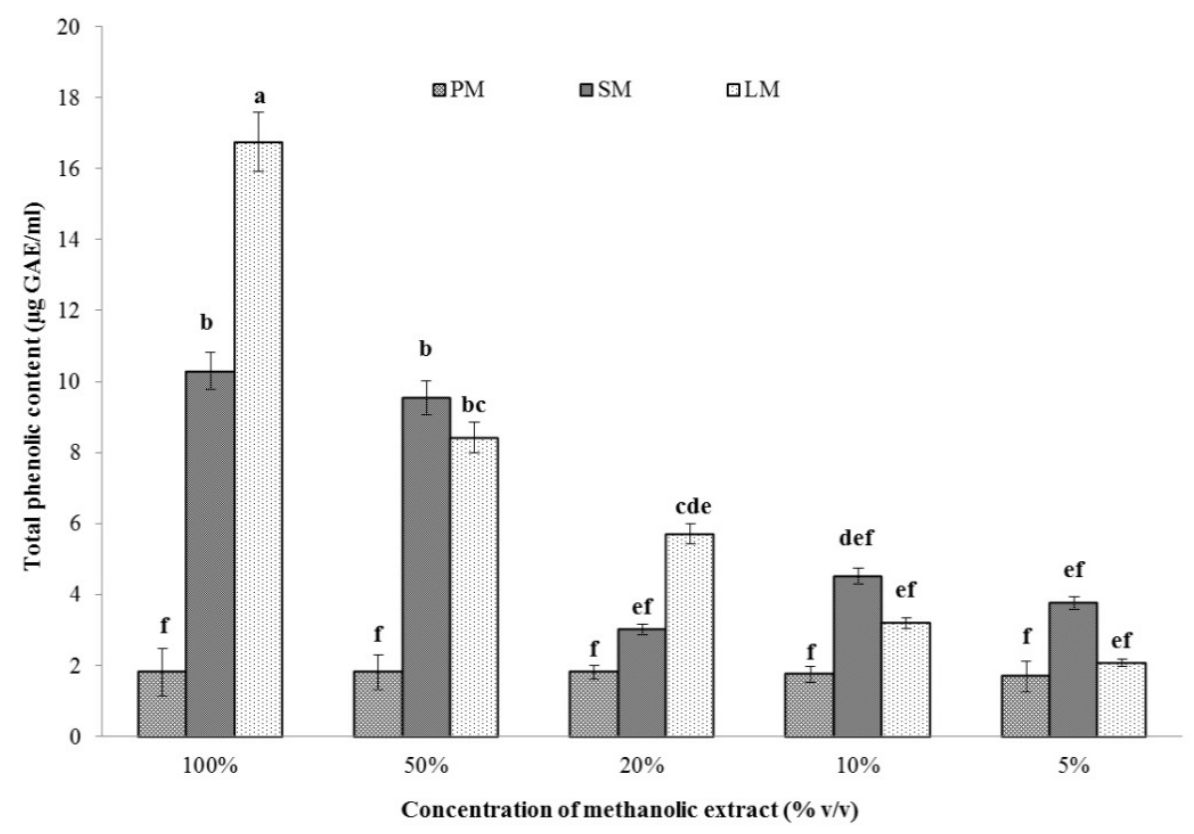

(a)

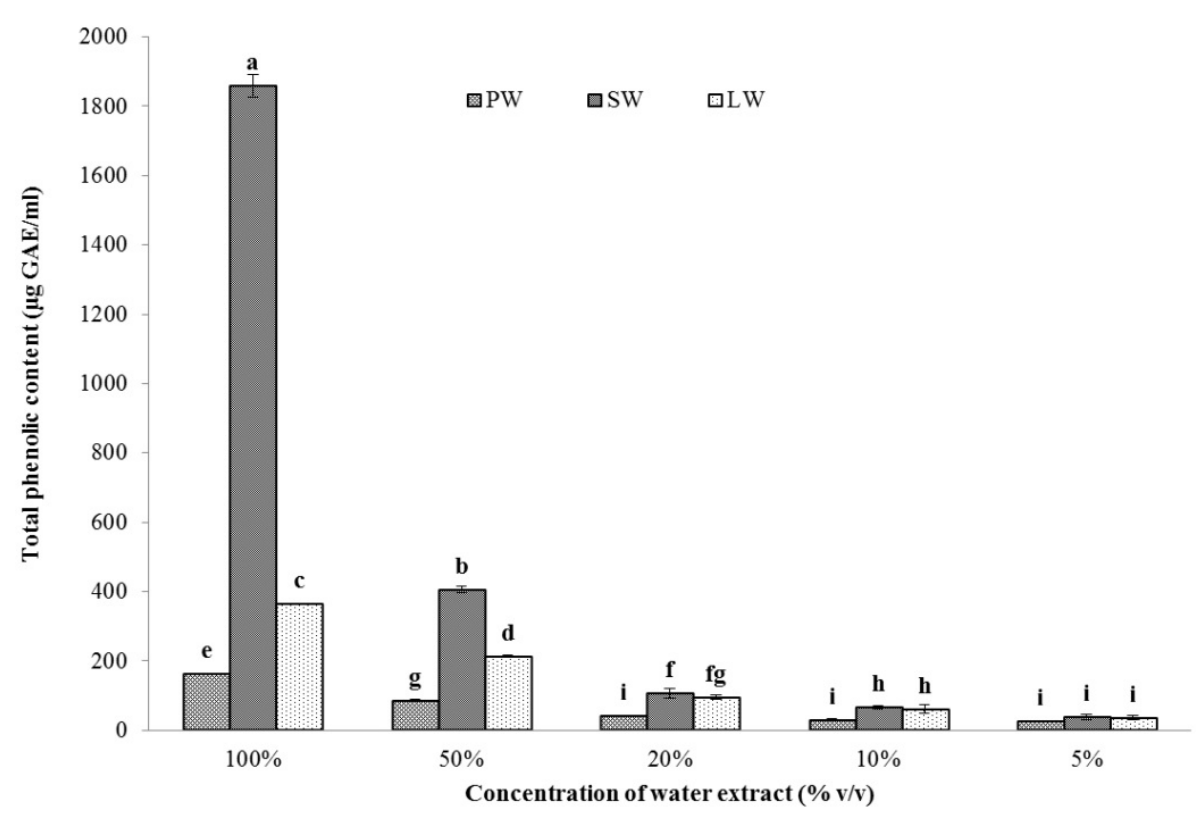

(b)

Figure 1. Total phenolic content of (a) methanolic and (b) water extracts of Pseudanabaena sp. (PM, PW), Lyngbya sp. (LM, LW), and Spirulina sp. (SM, SW) at different concentration $(n=3)$.

\subsubsection{Total Antioxidant Capacity (TAC)}

The total antioxidant capacity of the methanol and water extracts has been shown in Figure 2a,b, respectively. The native extracts were, again, diluted to get five different concentrations of the extracts. Similar to total phenolic content, water extracts LW and SW, again, showed a higher antioxidant activity. LW had an activity of $169.42 \pm 18.54 \mathrm{mg}$ ascorbic acid equivalents (AAE) $\mathrm{g}^{-1}$ dry mass. However, the anti-oxidant capacity of PW was higher than SW in this test $\left(49.92 \pm 1.11 \mathrm{mg} \mathrm{AAE} \mathrm{g}^{-1}\right.$ 
dry mass). In the case of the methanolic extracts, LM had the highest activity $(83.11 \pm 1.19 \mathrm{mg}$

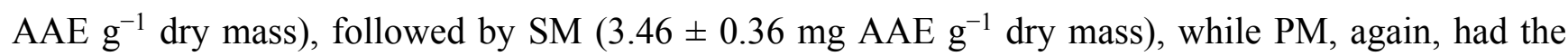
lowest activity of all the three extracts. The priority of water extraction over methanol, again, led to a higher activity in water extracts. Ganesan et al. have reported anti-oxidant capacities of extracts from Indian red seaweeds ranging from $0.31 \pm 0.1$ to $2.88 \pm 0.39 \mathrm{mg} \mathrm{AAE} \mathrm{g}^{-1}$ extract [26]. Additionally, Kumar et al. have studied the antioxidant capacities of 22 tropical seaweeds from India and found them within a range of $0.21 \pm 0.06$ to $1.14 \pm 0.16 \mathrm{mg} \mathrm{AAE}^{-1}$ extract [27]. Considering the significantly higher activities, the cyanobacterial extracts can be considered valuable antioxidants.

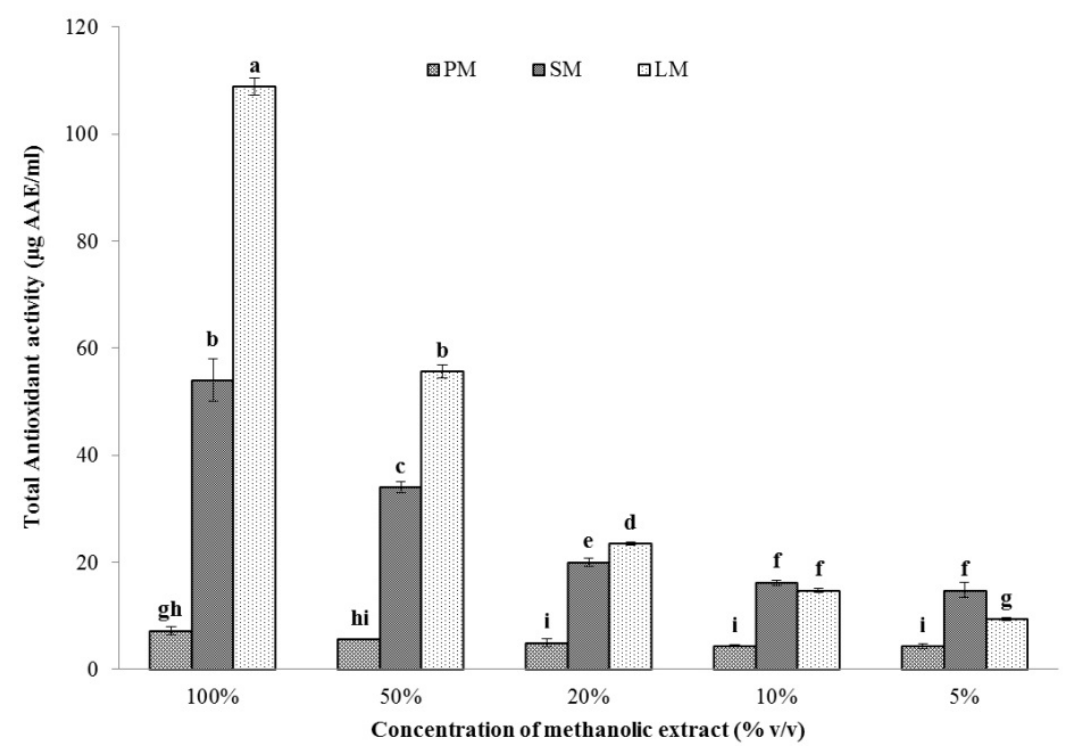

(a)

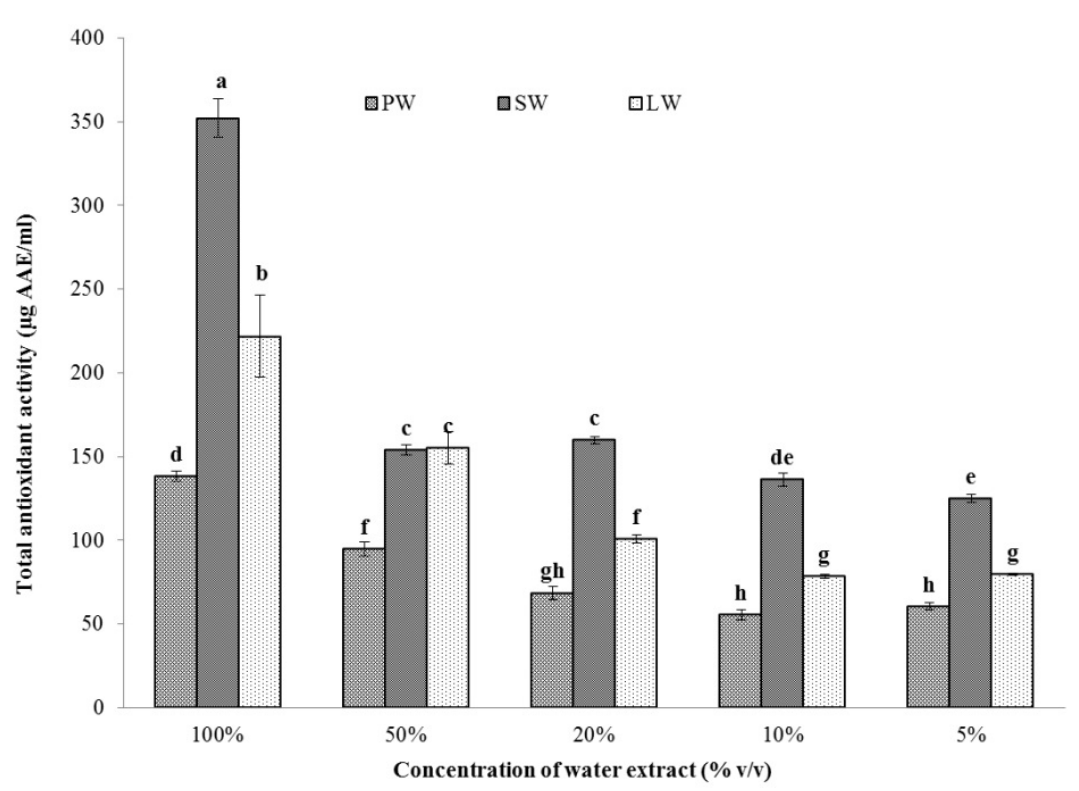

(b)

Figure 2. Total antioxidant capacity of (a) methanolic and (b) water extracts of Pseudanabaena sp. (PM, PW), Lyngbya sp. (LM, LW), and Spirulina sp. (SM, SW) at different concentrations $(n=3)$. 


\subsubsection{DPPH Scavenging Activity and EC50 Value}

The water and methanolic extracts were evaluated for their 2,2-diphenyl-1-picrylhydrazyl (DPPH) scavenging activity and the $\mathrm{EC}_{50}$ values were calculated on a dry mass basis. DPPH is a common free radical used to assess the radical scavenging activity of many extracts and antioxidants [28,29]. EC50 typically represents the amount of a compound needed to reduce the concentration of the free radical by half. A lower $\mathrm{EC}_{50}$ value signifies a better scavenging activity. The DPPH scavenging activity of the native extracts, as well as the corresponding EC50 value, has been shown in Table 2. LW was found to be the best scavenger of DPPH with an $\mathrm{EC}_{50}$ value of $18.78 \pm 1.57 \mathrm{mg}$ dry mass $\mathrm{mg}^{-1} \mathrm{DPPH}$, while LM was the best scavenger in case of methanolic extracts (EC 50 of $59.56 \pm 37.38 \mathrm{mg}$ dry mass mg ${ }^{-1}$ DPPH). The scavenging effect of both water and methanolic extracts shows that the antioxidant activity of the extracts is mainly due to the presence of pigments in them.

Table 2. TPC, TAC, and antioxidant activities of different cyanobacterial extracts $(n=3)$.

\begin{tabular}{|c|c|c|c|}
\hline Sample & $\begin{array}{c}\text { TPC (mg GAE } \mathrm{g}^{-1} \\
\text { dry mass) }\end{array}$ & $\begin{array}{c}\text { TAC (mg AAE } \mathrm{g}^{-1} \\
\text { dry mass) }\end{array}$ & $\begin{array}{c}\text { EC }_{50} \text { DPPH (mg dry } \\
\text { mass mg }^{-1} \text { DPPH) }\end{array}$ \\
\hline PW & $58.94 \pm 0.34$ & $49.92 \pm 1.11$ & $42.73 \pm 4.29$ \\
\hline SW & $119.19 \pm 2.09$ & $22.59 \pm 0.74$ & $148.46 \pm 21.17$ \\
\hline LW & $278.73 \pm 1.24$ & $169.42 \pm 18.54$ & $18.78 \pm 1.57$ \\
\hline PM & $0.65 \pm 0.24$ & $2.61 \pm 0.27$ & $1544.43 \pm 207.76$ \\
\hline SM & $0.66 \pm 0.3$ & $3.46 \pm 0.26$ & $728.55 \pm 667.73$ \\
\hline LM & $12.77 \pm 2.23$ & $83.11 \pm 1.19$ & $59.56 \pm 37.38$ \\
\hline
\end{tabular}

\subsection{Iso-Bolographic Studies}

The interaction of different extracts with each other and their effects on DPPH scavenging were studied using iso-bolographic studies (Table 3). Most of the extracts were antagonistic to each other with the theoretical sum of their $\mathrm{EC}_{50}$ values less than their corresponding experimental values. Synergistic effects were observed for the combinations of LM-SM, SM-PM, and SM-PW only. The descending order of synergy between different combinations were LM-SM 1:1 (86.65\%) > SM-PW 9:1 (83.18) > SM-PW 1:1 (82.2\%) > LM-SM 1:9 (75.18\%) > LW-SW 1:1 (64.6\%) > LM-SM 9:1 $(57.6 \%)>$ SW-PM 1:9 (48.88\%) > SM-PM 9:1 (42.74\%). The antagonistic effects observed in other combinations may be due to other proteins or compounds present in the water extracts, since most of the methanolic extracts have excellent synergy between them. Cyanobacteria have been reported to secrete various toxins that might have played a role during the combination of different extracts [30,31]. Little data is available on iso-bolographic studies conducted on plant extracts since most of the studies have been conducted on drug interactions. Jiang et al. have reported the use of iso-bolography for evaluating the synergistic and antagonistic effects of combinations of hydrophilic and lipophilic extracts of four vegetables [22]. They have reported that most of the combinations have high levels of synergy between them, with the lipophilic carrot-hydrophilic eggplant 1:1 combination having 87.4\% synergistic rate, which is similar to our observation for LM-SM 1:1. 
Table 3. DPPH activities of different cyanobacterial extracts in combination $(n=3) *$.

\begin{tabular}{|c|c|c|c|c|}
\hline Combination of Extracts & Fraction & $\begin{array}{l}\text { Theoretical EC } 50 \\
\left(\mathrm{mg} \mathrm{mg}^{-1} \text { DPPH) }\right.\end{array}$ & $\begin{array}{c}\text { Experimental EC } \mathrm{C}_{50} \\
\left(\mathrm{mg} \mathrm{mg}^{-1} \mathrm{DPPH}\right)\end{array}$ & $\begin{array}{c}\text { Synergistic } \\
\text { Rate (\%) }\end{array}$ \\
\hline \multirow{3}{*}{ LW-PW } & F1/9 & 40.33 & $185.21 \pm 9.23^{\mathrm{a}}$ & -359.20 \\
\hline & $\mathrm{F} 5 / 5$ & 30.75 & $55.88 \pm 22.17^{\mathrm{a}}$ & -81.71 \\
\hline & F9/1 & 21.17 & $26.96 \pm 11.99^{\mathrm{a}}$ & -27.36 \\
\hline \multirow{3}{*}{ PW-SW } & F1/9 & 137.89 & $261.88 \pm 111.67^{\mathrm{a}}$ & -89.92 \\
\hline & $\mathrm{F} 5 / 5$ & 95.59 & $130.93 \pm 55.45^{\mathrm{a}, \mathrm{b}}$ & -36.97 \\
\hline & F9/1 & 53.30 & $88.15 \pm 63.01^{b}$ & -65.38 \\
\hline \multirow{3}{*}{ LW-SW } & F1/9 & 135.49 & $242.33 \pm 120.34^{\mathrm{a}}$ & -78.85 \\
\hline & $\mathrm{F} 5 / 5$ & 83.62 & $29.60 \pm 5.18^{b}$ & 64.60 \\
\hline & F9/1 & 31.75 & $32.34 \pm 17.66^{b}$ & -1.88 \\
\hline \multirow{3}{*}{ LM-SM } & F1/9 & 661.65 & $164.23 \pm 84.79^{\mathrm{a}}$ & 75.18 \\
\hline & $\mathrm{F} 5 / 5$ & 394.06 & $52.60 \pm 17.10^{\mathrm{a}}$ & 86.65 \\
\hline & F9/1 & 126.46 & $53.63 \pm 30.31^{\mathrm{a}}$ & 57.60 \\
\hline \multirow{3}{*}{ LM-PM } & F1/9 & 1395.94 & $5371.82 \pm 628.95^{\mathrm{a}}$ & -284.82 \\
\hline & $\mathrm{F} 5 / 5$ & 802.00 & $883.11 \pm 89.96^{\mathrm{a}}$ & -10.11 \\
\hline & F9/1 & 208.05 & $1388.47 \pm 320.20^{\mathrm{a}}$ & -567.37 \\
\hline \multirow{3}{*}{ SM-PM } & F1/9 & 1462.84 & $1141.63 \pm 427.18^{a}$ & 21.96 \\
\hline & $\mathrm{F} 5 / 5$ & 1136.49 & $726.50 \pm 58.38^{a}$ & 36.07 \\
\hline & F9/1 & 810.14 & $463.86 \pm 82.31^{\mathrm{a}}$ & 42.74 \\
\hline \multirow{3}{*}{ LW-SM } & F1/9 & 657.57 & $587.30 \pm 93.65^{\mathrm{a}}$ & 10.69 \\
\hline & $\mathrm{F} 5 / 5$ & 373.66 & $595.09 \pm 112.33^{a}$ & -59.26 \\
\hline & F9/1 & 89.75 & $71.10 \pm 52.77^{\mathrm{a}}$ & 20.79 \\
\hline \multirow{3}{*}{ SW-PM } & F1/9 & 1404.83 & $718.10 \pm 82.43^{a}$ & 48.88 \\
\hline & $\mathrm{F} 5 / 5$ & 846.45 & $1242.09 \pm 204.02^{a}$ & -46.74 \\
\hline & F9/1 & 288.06 & $450.80 \pm 198.58^{\mathrm{a}}$ & -56.50 \\
\hline \multirow{3}{*}{ PW-LM } & $\mathrm{F} 1 / 9$ & 57.88 & $50.28 \pm 23.22^{a}$ & 13.13 \\
\hline & $\mathrm{F} 5 / 5$ & 51.15 & $176.53 \pm 26.72^{\mathrm{a}}$ & -245.15 \\
\hline & F9/1 & 44.41 & $53.35 \pm 18.67^{\mathrm{a}}$ & -20.13 \\
\hline \multirow{3}{*}{ LM-SW } & F1/9 & 139.57 & $171.74 \pm 74.87^{\mathrm{a}}$ & -23.05 \\
\hline & $\mathrm{F} 5 / 5$ & 104.01 & $690.94 \pm 57.20^{\mathrm{a}, \mathrm{b}}$ & -564.29 \\
\hline & F9/1 & 68.45 & $70.23 \pm 13.17^{\mathrm{b}}$ & -2.60 \\
\hline \multirow{3}{*}{ PM-LW } & F1/9 & 171.34 & $220.12 \pm 45.49^{\mathrm{a}}$ & -28.47 \\
\hline & $\mathrm{F} 5 / 5$ & 781.60 & $858.59 \pm 166.33^{a}$ & -9.85 \\
\hline & F9/1 & 1391.87 & $1908.85 \pm 388.08^{a}$ & -37.14 \\
\hline \multirow{3}{*}{ SM-PW } & F1/9 & 111.31 & $94.51 \pm 51.36^{\mathrm{a}}$ & 15.09 \\
\hline & $\mathrm{F} 5 / 5$ & 385.64 & $68.65 \pm 25.04^{\mathrm{a}}$ & 82.20 \\
\hline & F9/1 & 659.97 & $111.03 \pm 78.97^{\mathrm{a}}$ & 83.18 \\
\hline
\end{tabular}

* Values with different letters $(\mathrm{a}, \mathrm{b})$ in the same column show significant difference $(p<0.05)$.

\subsection{In Vitro Digestibility Studies}

In vitro digestion mimics the enzymes and their optimum physico-chemical conditions found in our gastro-intestinal tract. It provides an excellent alternate to animal feeding experiments to observe the changes taking place in a food item after ingestion. We investigated the effect of simulated digestion 
on the cyanobacterial extracts according to the protocol detailed in Section 3.5. All of the water extracts showed reduced DPPH scavenging after digestion (Figure 3). The probable reason would be the degradation of the amino acid backbone of the proteins in the water extract due to the presence of pepsin in gastric and pancreatin in duodenal solution. To the best of our knowledge, no studies on in vitro digestion of cyanobacterial extracts containing phycobiliproteins and carotenoids have been reported, which is an excellent avenue for further research. However, there is a recent report of R-phycoerythrin (R-PE) from Bangia fusco-purpurea that gave higher values of DPPH radical scavenging activities after digestion. The reason was the formation of short peptides after digestion in which the hydrophobic amino acid residues were more exposed to DPPH radical and contributed to the overall anti-oxidant activity [32]. Among the methanol extracts SM showed a considerable decrease in the scavenging activity while PM and LM were relatively unchanged. Though no study has reported the in vitro digestibility studies of methanolic extracts of microalgae, the digestion of $\beta$-carotene alone has previously been carried out. According to reports on human digestion studies, $\beta$-carotene absorption is highly variable and inefficient due to their high hydrophobicity and consequently, less solubility in aqueous systems [15]. This is the probable reason for the unchanged activities of methanolic extracts of PM and LM.

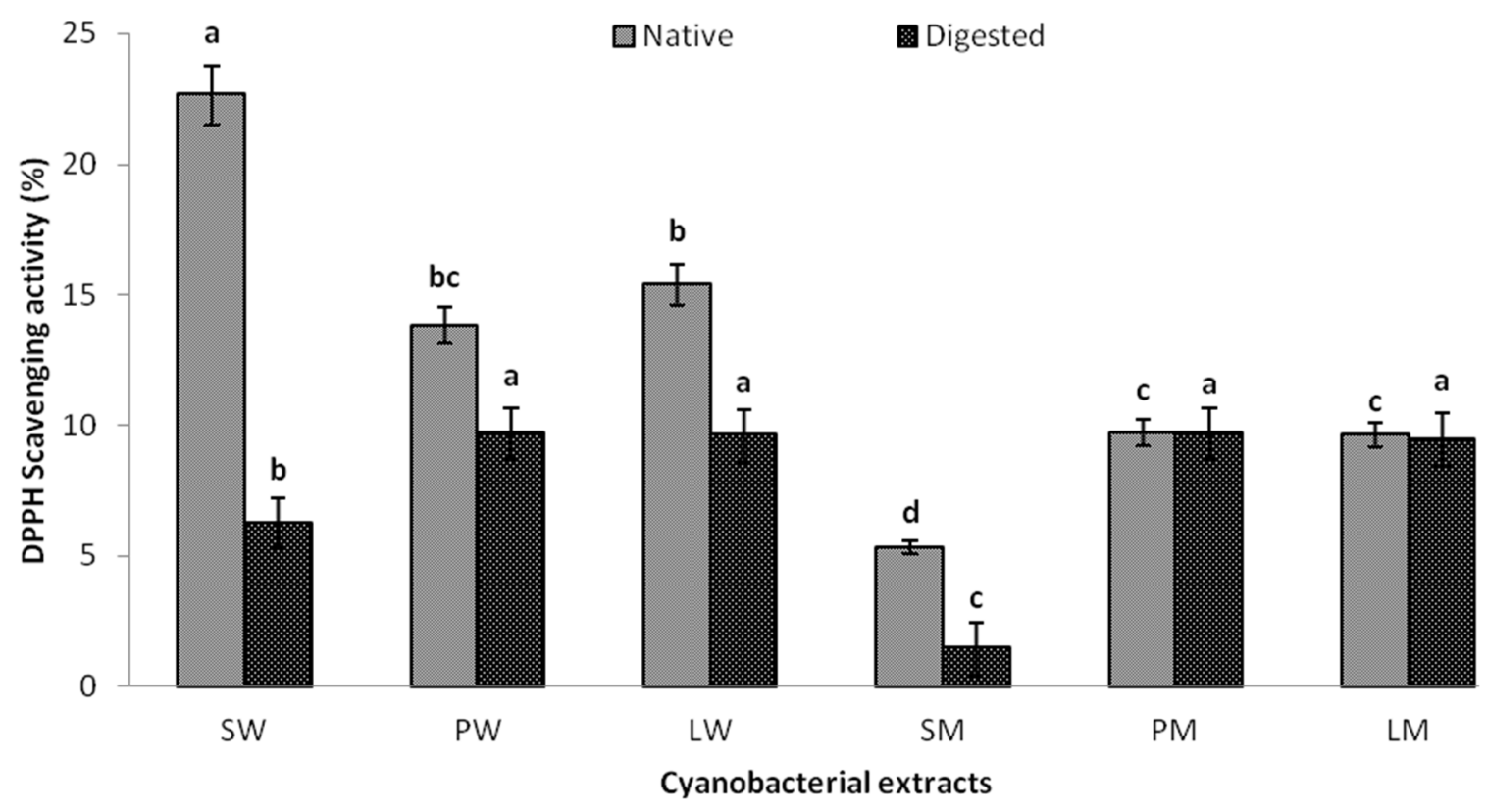

Figure 3. DPPH scavenging activity of water and methanolic extracts of Pseudanabaena sp., Lyngbya sp. and Spirulina sp. before and after digestion.

\subsection{Effect of Water and Methanolic Extracts on Calcium Oxalate Crystallization}

The formation of calcium oxalate and other types of crystals is a common cause of urolithiasis, more commonly known as urinary stones. Approximately $10 \%$ of the world's population is affected by it, out of which around $90 \%$ of the cases are related to the formation of calcium oxalate crystals. There are currently no drugs available for its treatment. The supersaturation of urine by calcium oxalate is a central process to the stone formation activity in which two separate processes, crystal nucleation, and crystal aggregation, are involved. When the supersaturation exceeds the limit of metastability, calcium 
and oxalate form clusters that are the core of the crystals (nucleation). The addition of new ions to this core causes the crystals to grow in size, after which they start merging into one another to form the macroscopic stones (aggregation). The processes of nucleation and aggregation can be evaluated through observing the kinetics of a metastable solution of calcium and oxalate maintained at physiological $\mathrm{pH}$-value and temperature. It is also possible to calculate the rates of nucleation and aggregation through observing the optical density of the solution at $620 \mathrm{~nm}$. Figure 4 shows the rates of inhibition of nucleation and aggregation of calcium oxalate in the presence or absence of our test samples compared to the negative control. The cyanobacterial water extracts were able to inhibit the nucleation and aggregation processes up to $84.43 \% \pm 0.44 \%$ and $77.97 \% \pm 0.66 \%$, respectively. The corresponding values in the methanolic extracts were $82.49 \% \pm 0.55 \%$ and $77.10 \% \pm 0.66 \%$. Tri-sodium citrate was taken as the positive control and inhibited the nucleation and aggregation processes by $51.52 \% \pm 0.01 \%$ and $42.03 \% \pm 1.33 \%$, respectively. Different extracts used in our study influenced the crystallization process in different ways. For example, the extracts of Lyngbya sp. inhibit the process of nucleation significantly more than they inhibit aggregation. Overall, the PW and SM extracts inhibit both nucleation and aggregation almost equally and are the optimum choices (Supplementary Table 1). There are no studies available on the calcium oxalate crystallization assay of microalgal extracts whereas Teodesio Melo et al., have investigated the anti-stone activity of sulphated polysaccharides from brown seaweed Dictyopteris justii wherein they have obtained inhibition rates of close to $80 \%-85 \%$ for both nucleation and aggregation [33]. Similar rates for both these processes were observed in our native extracts. Further, Zhang et al. have reported similar values of inhibition of nucleation and aggregation when they utilized sulphated polysaccharides from another brown seaweed, Sargassum graminifolium [13].

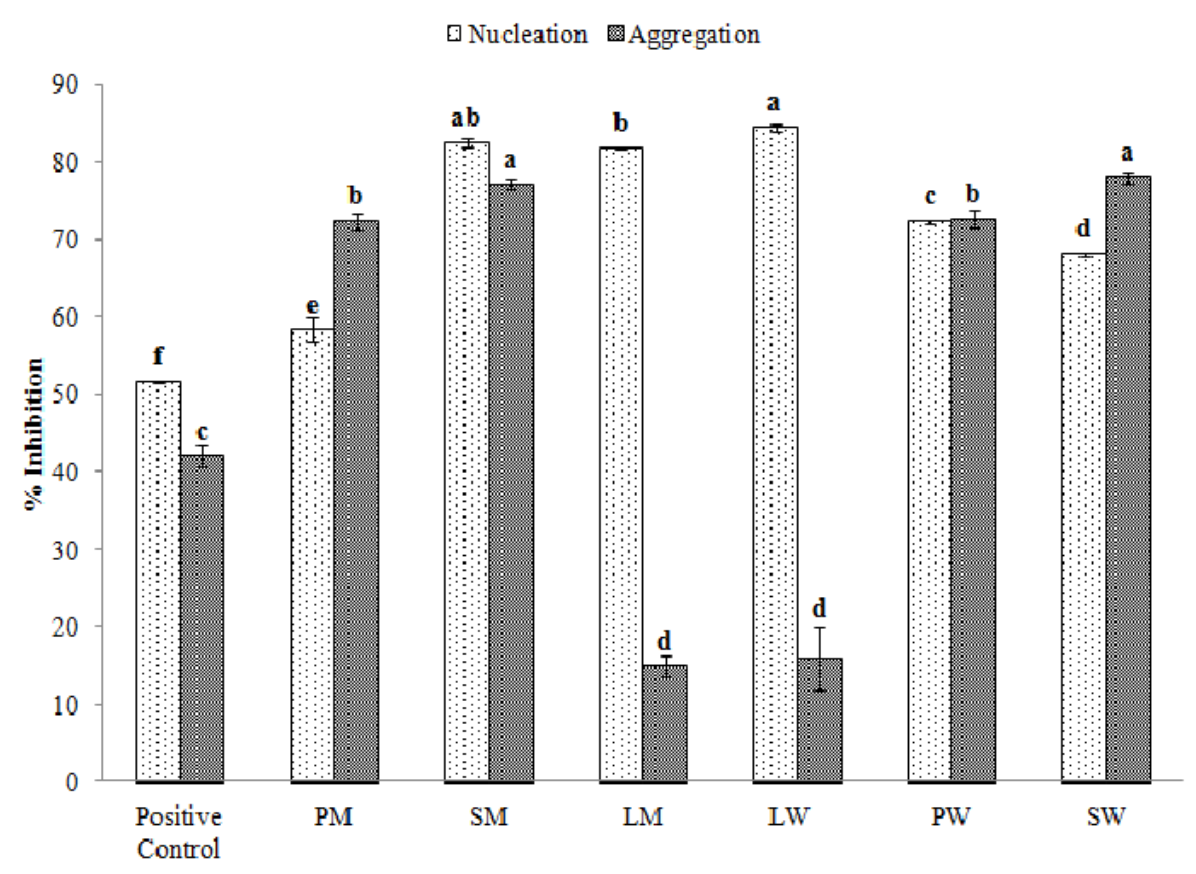

Figure 4. \% inhibition of nucleation and aggregation of calcium oxalate crystals by different extracts (PM: Pseudanabaena sp. methanol extract, SM: Spirulina sp. methanol extract, LM: Lyngbya sp. methanol extract, LW: Lyngbya sp. water extract, PW: Pseudanabaena sp. water extract, SW: Spirulina sp. water extract). 
The morphology of the crystals have been shown in Figure 5a-h. The crystal size in the negative control is approximately $12 \mu \mathrm{m}$ in size (Figure 5a) while the test samples (Figure $5 \mathrm{~b}-\mathrm{h}$ ) were able to reduce the size of the crystals by almost $60 \%-65 \%$ (approximately $3-4 \mu \mathrm{m}$ ). Such types of crystals can be more easily excreted out from the body during the passage of urine. The observation is also supported by the significant inhibition of nucleation and aggregation processes (Figure 4).

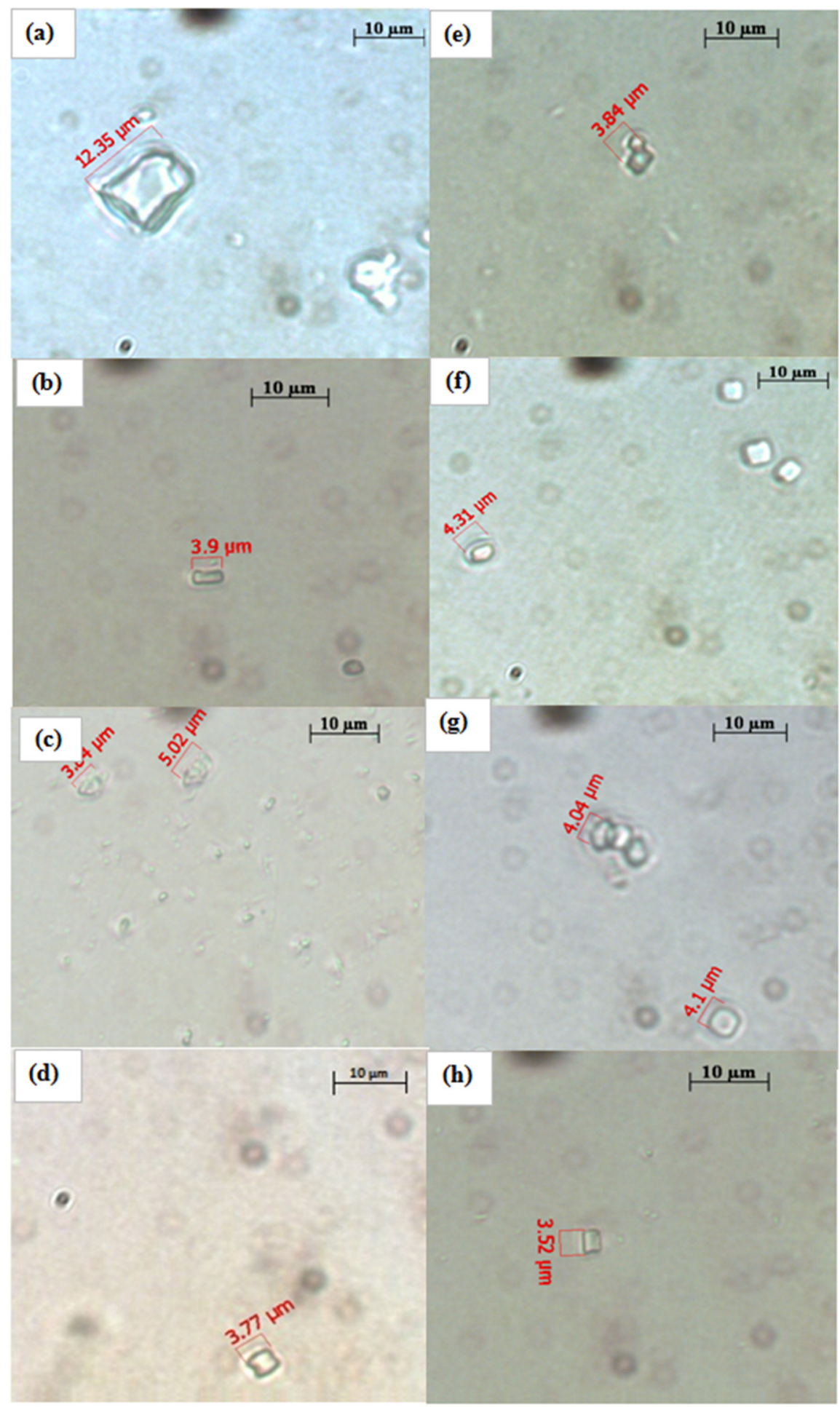

Figure 5. $\mathrm{CaOx}$ crystals observed under inverted microscope $(100 \times)$ formed in the metastable solution of $\mathrm{CaOx}$ in the (a) absence of sample and the presence of (b) PM; (c) SM; (d) LM; (e) trisodium citrate; (f) PW; (g) SW; (h) LW. 


\section{Experimental Section}

\subsection{Preparation of Extracts}

Spirulina sp. was grown in Zarrouk's medium, while Pseudanabaena sp. and Lyngbya sp. were both grown in ASN III medium according to earlier published reports [18,34]. The biomass was harvested after 18 days through centrifugation $\left(10,000 \times \mathrm{g}, 10 \mathrm{~min}, 10^{\circ} \mathrm{C}\right.$, Kubota Corporation, Japan) and washed thoroughly with distilled water to remove salt and particulates. The wet biomass was directly taken for extraction of pigments.

Water extracts: The harvested biomass was freeze thawed repeatedly in distilled water $\left(-70{ }^{\circ} \mathrm{C}\right.$ followed by $25^{\circ} \mathrm{C}$ ). After approximately 5-6 cycles of freeze thaw, the extract was centrifuged $\left(10,000 \times g, 10 \mathrm{~min}, 4^{\circ} \mathrm{C}\right)$ and was stored at $-80^{\circ} \mathrm{C}$ until further experiments.

Methanol extracts: Pre-weighed lyophilized microalgal biomass (approximately 100-200 mg) left after the water extraction process was dissolved in $5 \mathrm{~mL}$ of $99.9 \%$ pure methanol and vortexed thoroughly to increase the solvent contact time for maximum carotenoid extraction. The suspensions were incubated at $45{ }^{\circ} \mathrm{C}$ for $24 \mathrm{~h}$ in the dark, as described in Pancha et al. [35]. After $24 \mathrm{~h}$, the extract was centrifuged at $10,000 \times g$ for $5 \mathrm{~min}\left(4^{\circ} \mathrm{C}\right)$ to remove the cell debris and the supernatants were stored at $-80{ }^{\circ} \mathrm{C}$ until further experiments.

\subsection{Characterization of Water and Methanol Extracts}

The spectra of the water extracts were recorded from 250 to $700 \mathrm{~nm}$ in a microplate reader (SpectraMAX 190, Molecular Devices Inc., Sunnyvale, CA, USA). The concentrations of C-PC, Allophycocyanin (APC) and C-PE were calculated using the equations of Bennett and Bogorad [36]:

$$
\begin{gathered}
\mathrm{C}-\mathrm{PC}\left(\mathrm{mg} \cdot \mathrm{mL}^{-1}\right)=\left[\mathrm{A}_{615}-0.474 \mathrm{~A}_{652}\right] / 5.34 \\
\mathrm{~A}-\mathrm{PC}\left(\mathrm{mg} \cdot \mathrm{mL}^{-1}\right)=\left[\mathrm{A}_{652}-0.208 \mathrm{~A}_{615}\right] / 5.09 \\
\text { C-PE }\left(\mathrm{mg} \cdot \mathrm{mL}^{-1}\right)=\left[\mathrm{A}_{562}-2.41(\mathrm{C}-\mathrm{PC})-0.849(\mathrm{~A}-\mathrm{PC})\right] / 9.62
\end{gathered}
$$

The methanol extracts were analyzed through a Shimadzu HPLC system equipped with a diode array detector using a modified method described by Anderrson et al. [37]. The samples were eluted with a binary solvent gradient with Solvent A (v/v), a mixture of $80 \%$ acetonitrile, $15 \% \mathrm{MeOH}$ and $5 \%$ dichloromethane and Solvent B (v/v), a mixture of $30 \%$ acetonitrile, $20 \% \mathrm{MeOH}$ and $50 \%$ dichloromethane. The flow rate was $1 \mathrm{ml} / \mathrm{min}$ with the gradient flow of $0 \% \mathrm{~B}(0-2 \mathrm{~min}), 0 \%-25 \% \mathrm{~B}$ (2-15 min), 25\%-60\% B (15-17 min), 60\%-90\% B (17-29 min), 90\% B (29-39 min), 90\%-0\% B (39-41 $\mathrm{min})$, and $0 \% \mathrm{~B}(41-47 \mathrm{~min})$ in a $4.6 \times 250 \mathrm{~mm}$ TSKgel ODS $120 \mathrm{~T}$ column (Tosoh Corporation, Japan). Samples were analyzed using the retention times of carotenoid and chlorophyll standards obtained from DHI, Denmark. The diode array detector was set at $437 \mathrm{~nm}$ and concentrations were quantified based on the standard area. 


\subsection{Antioxidant Activities}

\subsubsection{Total Phenolic Content}

The total phenolic content was measured by Folin-Ciocalteu method [38]. In detail, $1 \mathrm{~mL}$ of the diluted sample was mixed with $4 \mathrm{~mL}$ of $7.5 \%$ (w/v) freshly prepared $\mathrm{Na}_{2} \mathrm{CO}_{3}$ and $1 \mathrm{~mL}$ of $10 \mathrm{x}$ diluted Folin-Ciocalteu reagent (Sigma Aldrich, St Louis, USA) and incubated at room temperature for $2 \mathrm{~h}$. The absorbance of the samples was read at $760 \mathrm{~nm}$ against a reagent blank and the phenolic content

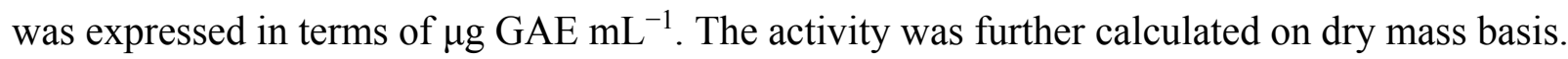

\subsubsection{Total Antioxidant Activity}

The total antioxidant activity of the cyanobacterial extracts were analyzed through a modified method given by Ganesan et al. [26]. Briefly, $1 \mathrm{~mL}$ of sample extract and $3 \mathrm{~mL}$ of phospho-molybdate reagent (1.1 $\mathrm{M} \mathrm{H}_{2} \mathrm{SO}_{4}, 30 \mathrm{mM} \mathrm{NaH} \mathrm{PO}_{4}$ and $4 \mathrm{mM}$ ammonium heptamolybdate) was mixed and incubated at $95{ }^{\circ} \mathrm{C}$ for $90 \mathrm{~min}$. After the reaction, the mixture was allowed to cool before their absorbance was read at $695 \mathrm{~nm}$. Ascorbic acid was taken as the standard. The anti-oxidant capacities of the extracts were expressed in terms of $\mathrm{mg} \mathrm{AAE} \mathrm{mL}^{-1}$. The activity was calculated on a dry mass basis.

\subsubsection{DPPH Assay}

The DPPH scavenging activity measurement was performed using a modification of the method described by Siler et al. [39]. Briefly, $1 \mathrm{~mL}$ of a $60 \mu \mathrm{M}$ methanolic DPPH solution was incubated with $100 \mu \mathrm{L}$ of the test samples or water for $30 \mathrm{~min}$ in the dark. The absorbance was recorded at $517 \mathrm{~nm}$ against a blank. The \% DPPH scavenging activity was measured by using following equation:

$$
\text { Scavenging effect } \left.=\left[\left(A_{\text {control }}-A_{\text {sample }}\right) / A_{\text {control }}\right)\right] \times 100 \%
$$

\subsection{Iso-Bolographic Studies}

Iso-bolographic studies of the various extracts were carried out according to the method described by Jiang et al., [22]. The water and methanol extracts of all the three cyanobacterial species were mixed in three different fractions. LM-SM fraction F $1 / 9$ signifies that 1 part of LM has been mixed with 9 parts of SM. Each of the fractions was analyzed for their DPPH scavenging activity as detailed in Section 3.4 and their experimental $\mathrm{EC}_{50}$. The theoretical $\mathrm{EC}_{50}$ values were calculated using the equation:

$$
\text { Theoretical } \mathrm{EC}_{50} \text { value }=f A+(1-f) B
$$

where $\mathrm{A}$ and $\mathrm{B}$ are the $\mathrm{EC}_{50}$ values of the individual extracts. The synergistic rate was calculated using the equation:

$$
\mathrm{SR}=\frac{\mathrm{TV}-\mathrm{EV}}{\mathrm{TV}} \times 100
$$

where TV and EV are the theoretical and experimental EC50 values of free radical scavenging, respectively. 


\subsection{In Vitro Digestibility of Different Extracts}

In vitro digestibility studies were performed on water and methanol free extracts by using a modification of the method described by Hur et al. [40]. $5 \mathrm{~mL}$ of each extract was mixed with $6 \mathrm{~mL}$ simulated saliva ( $\mathrm{pH}$-value $\sim 6.8$ ) and incubated at $37^{\circ} \mathrm{C}$ for $5 \mathrm{~min}$; thereafter, $12 \mathrm{~mL}$ of simulated gastric juice ( $\mathrm{pH}$-value $\sim 2$ ) was added and the solution was incubated $37{ }^{\circ} \mathrm{C}$ for $120 \mathrm{~min}$. In the final step, the sample mixture was mixed with simulated intestinal juice $(12 \mathrm{~mL}$ duodenal juice $+6 \mathrm{~mL}$ bile juice, $\mathrm{pH}$-value 8 ) and was incubated at $37^{\circ} \mathrm{C}$ for $120 \mathrm{~min}$. The samples were shaken in an incubator shaker (Jeio Tech, South Korea) at $80 \mathrm{rpm}$ throughout the experiment. $1 \mathrm{~mL}$ of the sample was withdrawn and the reaction was stopped by addition of $4 \mathrm{~mL}$ absolute ethanol. The final digested samples were stored at $-80{ }^{\circ} \mathrm{C}$ for analyzing their DPPH scavenging and anti-stone activities.

\subsection{Calcium Oxalate Crystallization Assay}

The effect of native and digested extracts of the three cyanobacterial species was evaluated using the calcium oxalate crystallization assay as described by Zhang et al. [13]. The assay quantifies the rate of formation and aggregation of calcium oxalate crystals and the efficacy of the test substances in hindering their formation by monitoring the kinetics of a metastable solution of calcium and oxalate ions at $620 \mathrm{~nm}$. The slopes used for the calculation of nucleation and aggregation rates were designated as $\mathrm{S}_{\mathrm{N}}$ and $\mathrm{S}_{\mathrm{A}}$, respectively. The percent inhibition for nucleation and aggregation were calculated by following equations:

$$
\begin{aligned}
& \text { Nucleation inhibition }(\%)=\left[1-\left(\mathrm{S}_{\mathrm{Nm}} / \mathrm{S}_{\mathrm{Nc}}\right)\right] \times 100 \\
& \text { Aggregation inhibition }(\%)=\left[1-\left(\mathrm{S}_{\mathrm{Am}} / \mathrm{S}_{\mathrm{Ac}}\right)\right] \times 100
\end{aligned}
$$

where $\mathrm{m}$ signifies the test material and c signifies control (tri-sodium citrate). The morphology and formation of crystals were observed using bright field microscopy (Carl Zeiss, Germany) at a magnification of $100 \times$.

\subsection{Statistical Analysis}

All experiments were performed in triplicate and the results are shown in mean $\pm \mathrm{SD}$. Analysis of variance was conducted using Fischer LSD test (Info Stat 3.0). The differences were calculated to be significant at $p<0.05$.

\section{Conclusions}

The water and methanolic extracts of cyanobacterial biomass were found to have good free radical scavenging activities both individually, as well as in combination with each other. The DPPH scavenging activities agreed well with the phenolic content and total antioxidant capacity of the individual extracts. However, in the iso-bolographic studies, except for a few fractions, they were mostly antagonistic to each other, signifying the fact that their antioxidant activities are optimum when they are taken individually. The complex nature of the individual extracts could play a role in this phenomenon, but it cannot be conclusively proven and needs further study. The native extracts were also found to inhibit the formation of calcium oxalate crystals in a range of $58 \%-84 \%$ for crystal 
nucleation and 15\%-78\% in crystal aggregation. Morphological observations of the crystals prove that the size of the crystals is reduced when the extracts, whether native or digested, are added to the solution. However, the digested water extracts displayed considerably less DPPH scavenging activity which needs to be correlated with the digestion products formed. With the exception of Spirulina sp., the methanol extracts show nearly identical DPPH scavenging activities both before and after digestion, suggesting that carotenoids are not majorly affected by the digestion process and their antioxidant activity stems from their assimilation.

\section{Acknowledgments}

This manuscript has been assigned PRIS number CSIR-CSMCRI-084/2015. Chetan Paliwal, Tonmoy Ghosh and Rahulkumar Maurya gratefully acknowledge CSIR, New Delhi for awarding Senior Research Fellowship. All the authors also acknowledge CSIR for providing the financial support through projects CSC 0203, OLP 0040 and OLP 0071. The authors would also like to thank Arvind Kumar (CSIR-CSMCRI, Bhavnagar) for his constant encouragement and Imran Pancha, Vamsi Bharadwaj SV and Kaumeel Chokshi for their constructive advice. The authors would like to thank Parimal Paul (CSIR-CSMCRI, Bhavnagar) and Harshad Brahmabhatt (CSIR-CSMCRI, Bhavnagar) for their timely help during the analysis. Chetan Paliwal, Tonmoy Ghosh and Rahulkumar Maurya wish to acknowledge AcSIR-CSMCRI for Ph.D. enrolment.

\section{Author Contributions}

Chetan Paliwal, Tonmoy Ghosh, Khushbu Bhayani and Rahulkumar Maurya have performed all the experiments and made substantial contributions to the acquisition and analysis of results. Chetan Paliwal, Tonmoy Ghosh and Sandhya Mishra have been involved in drafting and critical check of the entire manuscript. All authors have read and approved the final manuscript.

\section{Conflict of Interest}

The authors declare no conflict of interest.

\section{References}

1. Shishido, T.; Humisto, A.; Jokela, J.; Liu, L.; Wahlsten, M.; Tamrakar, A.; Fewer, D.; Permi, P.; Andreote, A.; Fiore, M.; et al. Antifungal compounds from cyanobacteria. Mar. Drugs 2015, 13, 2124-2140.

2. Guschina, I.A.; Harwood, J.L. Lipids and lipid metabolism in eukaryotic algae. Prog. Lipid Res. 2006, 45, 160-186.

3. Miyamoto, K. Renewable Biological Systems for Alternative Sustainable Energy Production; FAO: Osaka, Japan, 1997.

4. Sekar, S.; Chandramohan, M. Phycobiliproteins as a commodity: Trends in applied research, patents and commercialization. J. Appl. Phycol. 2008, 20, 113-136.

5. Fabregas, J.; Herrero, C. Vitamin content of four marine microalgae. Potential use as source of vitamins in nutrition. J. Ind. Microbiol. 1990, 5, 259-263. 
6. Mishra, A.; Kavita, K.; Jha, B. Characterization of extracellular polymeric substances produced by micro-algae Dunaliella salina. Carbohydr. Polym. 2011, 83, 852-857.

7. Hirschberg, J.; Chamovitz, D. Carotenoids in cyanobacteria. In The Molecular Biology of Cyanobacteria; Bryant, D.A., Ed.; Advances in Photosynthesis and Respiration; Springer: Dordrecht, The Netherlands, 2004; Volume 1, pp. 559-579.

8. Koller, M.; Muhr, A.; Braunegg, G. Microalgae as versatile cellular factories for valued products. Algal Res. 2014, 6, 52-63.

9. Blanco, A.; Moreno, J.; Del Campo, J.; Rivas, J.; Guerrero, M. Outdoor cultivation of lutein-rich cells of Muriellopsis sp. in open ponds. Appl. Microbiol. Biotechnol. 2007, 73, 1259-1266.

10. Sonani, R.; Singh, N.; Awasthi, A.; Prasad, B.; Kumar, J.; Madamwar, D. Phycoerythrin extends life span and health span of Caenorhabditis elegans. AGE 2014, 36, 1-14.

11. Sonani, R.R.; Singh, N.K.; Kumar, J.; Thakar, D.; Madamwar, D. Concurrent purification and antioxidant activity of phycobiliproteins from Lyngbya sp. A09DM: An antioxidant and anti-aging potential of phycoerythrin in Caenorhabditis elegans. Process Biochem. 2014, 49, 1757-1766.

12. Wang, Y.; Cai, C.; Li, B.; Liu, C.; He, P. Photodynamic effect of two kinds of phycobiliproteins on human liver cancer cell line SMMC-7721 in vitro. Sheng Wu Gong Cheng Xue Bao 2009, 25, $1417-1423$.

13. Zhang, C.-Y.; Wu, W.-H.; Wang, J.; Lan, M.-B. Antioxidant properties of polysaccharide from the brown seaweed Sargassum graminifolium (Turn.), and its effects on calcium oxalate crystallization. Mar. Drugs 2012, 10, 119-130.

14. McClements, D.J.; Decker, E.A.; Park, Y.; Weiss, J. Structural design principles for delivery of bioactive components in nutraceuticals and functional foods. Crit. Rev. Food Sci. Nutr. 2009, 49, 577-606.

15. Wang, P.; Liu, H.-J.; Mei, X.-Y.; Nakajima, M.; Yin, L.-J. Preliminary study into the factors modulating $\beta$-carotene micelle formation in dispersions using an in vitro digestion model. Food Hydrocoll. 2012, 26, 427-433.

16. Golding, M.; Wooster, T.J. The influence of emulsion structure and stability on lipid digestion. Curr. Opin. Coll. Interface Sci. 2010, 15, 90-101.

17. Morist, A.; Montesinos, J.; Cusidó, J.; Gòdia, F. Recovery and treatment of Spirulina platensis cells cultured in a continuous photobioreactor to be used as food. Process Biochem. 2001, 37, 535-547.

18. Mishra, S.K.; Shrivastav, A.; Mishra, S. Preparation of highly purified C-phycoerythrin from marine cyanobacterium Pseudanabaena sp. Protein Expr. Purif. 2011, 80, 234-238.

19. Rodriguez, H.; Rivas, J.; Guerrero, M.G.; Losada, M. Nitrogen-fixing cyanobacterium with a high phycoerythrin content. Appl. Environ. Microbiol. 1989, 55, 758-760.

20. Aakermann, T.; Skulberg, O.M.; Liaaen-Jensen, S. A comparison of the carotenoids of strains of Oscillatoria and Spirulina (Cyanobacteria). Biochem. Syst. Ecol. 1992, 20, 761-769.

21. Singh, O.A. Diversity Analysis and PCR Based Molecular Characterization of Carotenoid Rich Oscillatorian Cyanobacteria of North Eastern (NE) Region of India. Ph.D. Thesis, Assam University, Assam, India, 27 February 2015. 
22. Jiang, H.; Li, H.; Yu, C.; Yang, T.; Hu, J.; Liu, R.; Deng, Z.-Y. The evaluation of antioxidant interactions among 4 common vegetables using isobolographic analysis. J. Food Sci. 2015, 80, C1162-C1169, doi:10.1111/1750-3841.12896.

23. Machu, L.; Misurcova, L.; Vavra Ambrozova, J.; Orsavova, J.; Mlcek, J.; Sochor, J.; Jurikova, T. Phenolic content and antioxidant capacity in algal food products. Molecules 2015, 20, 1118-1133.

24. Ismaiel, M.M.S.; El-Ayouty, Y.M.; Piercey-Normore, M.D. Antioxidants characterization in selected cyanobacteria. Ann. Microbiol. 2014, 64, 1223-1230.

25. Dai, J.; Mumper, R.J. Plant phenolics: Extraction, analysis and their antioxidant and anticancer properties. Molecules 2010, 15, 7313-7352.

26. Ganesan, P.; Kumar, C.S.; Bhaskar, N. Antioxidant properties of methanol extract and its solvent fractions obtained from selected Indian red seaweeds. Bioresour. Technol. 2008, 99, 2717-2723.

27. Kumar, M.; Kumari, P.; Trivedi, N.; Shukla, M.; Gupta, V.; Reddy, C.R. K.; Jha, B. Minerals, PUFAs and antioxidant properties of some tropical seaweeds from Saurashtra coast of India. J. Appl. Phycol. 2011, 23, 797-810.

28. Cervantes-Paz, B.; Yahia, E.M.; de Jesús Ornelas-Paz, J.; Victoria-Campos, C.I.; Ibarra-Junquera, V.; Pérez-Martínez, J.D.; Escalante-Minakata, P. Antioxidant activity and content of chlorophylls and carotenoids in raw and heat-processed Jalapeño peppers at intermediate stages of ripening. Food Chem. 2014, 146, 188-196.

29. Wang, K.; Li, W.; Rui, X.; Chen, X.; Jiang, M.; Dong, M. Structural characterization and bioactivity of released exopolysaccharides from Lactobacillus plantarum 70810. Int. J. Biol. Macromol. 2014, $67,71-78$.

30. Bláha, L.; Babica, P.; Maršálek, B. Toxins produced in cyanobacterial water blooms-Toxicity and risks. Interdiscip. Technol. 2009, 2, 36-41.

31. Carmichael, W.W.; Mahmood, N.A.; Hyde, E.G. Natural Toxins from Cyanobacteria (Blue-Green Algae). In Marine Toxins; Hall, S., Strichartz, G., Eds.; ACS Symposium Series; American Chemical Society: Washington, DC, USA, 1990; Volume 418, pp. 87-106.

32. Wu, Q.; Fu, X.-P.; Sun, L.-C.; Zhang, Q.; Liu, G.-M.; Cao, M.-J.; Cai, Q.-F. Effects of physicochemical factors and in vitro gastrointestinal digestion on antioxidant activity of R-phycoerythrin from red algae Bangia fusco-purpurea. Int. J. Food Sci. Technol. 2015, 50, 1445-1451.

33. Teodosio Melo, K.R.; Gomes Camara, R.B.; Queiroz, M.F.; Jacome Vidal, A.A.; Machado Lima, C.R.; Melo-Silveira, R.F.; Almeida-Lima, J.; Oliveira Rocha, H.A. Evaluation of sulfated polysaccharides from the brown seaweed Dictyopteris justii as antioxidant agents and as inhibitors of the formation of calcium oxalate crystals. Molecules 2013, 18, 14543-14563.

34. Patel, A.; Mishra, S.; Pawar, R.; Ghosh, P.K. Purification and characterization of C-Phycocyanin from cyanobacterial species of marine and freshwater habitat. Protein Expr. Purif. 2005, 40, 248-255.

35. Pancha, I.; Chokshi, K.; George, B.; Ghosh, T.; Paliwal, C.; Maurya, R.; Mishra, S. Nitrogen stress triggered biochemical and morphological changes in the microalgae Scenedesmus sp. CCNM 1077. Bioresour. Technol. 2014, 156, 146-154.

36. Bennett, A.; Bogorad, L. Complementary chromatic adaptation in a filamentous blue-green alga. J. Cell Biol. 1973, 58, 419-435. 
37. Andersson, S.C.; Rumpunen, K.; Johansson, E.; Olsson, M.E. Carotenoid content and composition in rose hips (Rosa spp.) during ripening, determination of suitable maturity marker and implications for health promoting food products. Food Chem. 2011, 128, 689-696.

38. Dudonné, S.; Vitrac, X.; Coutière, P.; Woillez, M.; Mérillon, J.-M. Comparative study of antioxidant properties and total phenolic content of 30 plant extracts of industrial interest using DPPH, ABTS, FRAP, SOD, and ORAC assays. J. Agric. Food Chem. 2009, 57, 1768-1774.

39. Šiler, B.; Živković, S.; Banjanac, T.; Cvetković, J.; Nestorović Živković, J.; Ćirić, A.; Soković, M.; Mišić, D. Centauries as underestimated food additives: Antioxidant and antimicrobial potential. Food Chem. 2014, 147, 367-376.

40. Hur, S.J.; Decker, E.A.; McClements, D.J. Influence of initial emulsifier type on microstructural changes occurring in emulsified lipids during in vitro digestion. Food Chem. 2009, 114, 253-262.

(C) 2015 by the authors; licensee MDPI, Basel, Switzerland. This article is an open access article distributed under the terms and conditions of the Creative Commons Attribution license (http://creativecommons.org/licenses/by/4.0/). 